\title{
The dynamics of deforestation and reforestation in a developing economy
}

\author{
Julien Wolfersberger ${ }^{1}$, Gregory S. Amacher ${ }^{2}$, Philippe Delacote ${ }^{3}$, \\ Arnaud Dragicevic ${ }^{4}$
}

Forest transition theory is often used to describe the long term evolution of forest cover in a country as it develops, yet previous theoretical work has considered only net forest cover change when describing deforestation. However, little work exists describing the dynamics involved in forest cover change, particularly the relationship between reductions in primary native forests commonly associated with deforestation and concomitant reforestation and establishment of secondary forest plantations. We examine this distinction and formulate a new forest transition hypothesis. Our approach recognizes that primary and secondary forests are imperfect substitutes in terms of ecosystem services, but also in the costs associated with securing tenure. The latter is important given the property rights insecurities that have led to deforestation in many tropical countries. Our model allows a study of both the length of a forest transition and the speed at which net forest depletion eventually ends in the long run. Understanding the forest transition as we describe it could be important for future climate change mitigation policies. For instance, we find that privileging the dynamics of reforestation can be harmful for primary native forests, which are known to have the highest ecological value.

JEL classification : 011- O13 - Q23 - Q56 - Q57.

Keywords : forest transition - land uses - development - tenure costs.

1. Chaire Economie du Climat, Palais Brongniart 28 place de la Bourse, 75002 Paris, France. INRA, UMR 356 Économie Forestière, F-54000 Nancy, France. AgroParisTech, Laboratoire d'Économie Forestière, 14 rue Girardet, 54042 Nancy Cedex France.

2. Virginia Polytechnic Institute and State University, 307 C Cheatham Hall, Blacksburg, VA 24601-0324, USA.

3. Chaire Economie du Climat, Palais Brongniart 28 place de la Bourse, 75002 Paris, France. INRA, UMR 356 Économie Forestière, F-54000 Nancy, France.

4. AgroParisTech, Laboratoire d'Économie Forestière, 14 rue Girardet, 54042 Nancy Cedex France.

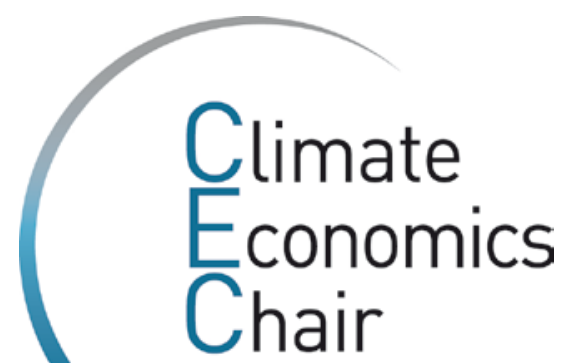

Paris-Dauphine University CDC Climat 
This page is intentionally blank - Cette page est laissée vide intentionnellement 


\title{
The dynamics of deforestation and reforestation in a developing economy
}

\author{
Julien Wolfersberger $\stackrel{* \dagger}{;}$ Gregory S. Amacher $\stackrel{\S}{\S}$ Philippe Delacote*†, Arnaud Dragicevic ${ }^{\ddagger}$
}

\begin{abstract}
Forest transition theory is often used to describe the long term evolution of forest cover in a country as it develops, yet previous theoretical work has considered only net forest cover change when describing deforestation. However, little work exists describing the dynamics involved in forest cover change, particularly the relationship between reductions in primary native forests commonly associated with deforestation and concomitant reforestation and establishment of secondary forest plantations. We examine this distinction and formulate a new forest transition hypothesis. Our approach recognizes that primary and secondary forests are imperfect substitutes in terms of ecosystem services, but also in the costs associated with securing tenure. The latter is important given the property rights insecurities that have led to deforestation in many tropical countries. Our model allows a study of both the length of a forest transition and the speed at which net forest depletion eventually ends in the long run. Understanding the forest transition as we describe it could be important for future climate change mitigation policies. For instance, we find that privileging the dynamics of reforestation can be harmful for primary native forests, which are known to have the highest ecological value.
\end{abstract}

Keywords: forest transition, land uses, development, tenure costs

JEL classification: O11, O13, Q23, Q56, Q57

\footnotetext{
${ }^{*}$ Chaire Economie du Climat, Palais Brongniart 28 place de la Bourse, 75002 Paris, France

${ }^{\dagger}$ INRA, UMR 356 Économie Forestière, F-54000 Nancy, France

‡AgroParisTech, Laboratoire d'Économie Forestière, 14 rue Girardet, 54042 Nancy Cedex France

$\S$ Virginia Polytechnic Institute and State University, 307 C Cheatham Hall, Blacksburg, VA 24601-0324, USA

${ }^{\top}$ Chaire Forêts pour Demain [Agro ParisTech-Office National des Forêts], 54042 Nancy Cedex, France
} 


\section{Introduction}

Deforestation is responsible for a significant amount of the world's $\mathrm{CO}_{2}$ emissions and represents one of the most serious threats to biodiversity preservation. In the long run, after deforestation has reached levels high enough, it is possible that net forest cover in a country could stop decreasing, and inherent in this idea is a point in time where forest cover starts to increase (Mather, 1992). Obviously such a point has already been reached in developed countries where previous large native forests were harvested during the industrial revolution. These forests have now been replaced with secondary managed and planted forests. Clearly, many tropical developing countries have not reached such a turning point where managed forests replace primary forest cover. While some developed countries such as France and the United States experienced this transition a few centuries ago, it is a current challenge for tropical developing economies which may still be very far from reaching the transition point. While most of the deforestation literature has focused only on replacement of primary forests with non-forest land uses, such as agriculture or grazing, to understand the forest transition one must also understand that net forest cover is composed of two distinct forest stocks: primary native (i.e. natural old-growth forests) and secondary forests (i.e. regeneration and plantations established through reforestation). During development, the former decreases while the latter increases. Since primary and secondary forests are not perfect substitutes, in terms of carbon storage, biodiversity and livelihoods, and costs of securing tenure, integrating this specification within the forest transition framework is an important consideration.

For example, Hartwick et al. (2001) studied the allocation of land uses between forest and agriculture, along with development in a small open economy allowing for the possibility of retimbering of lands, but important properties of FT were not examined. Barbier et al. (2005) used an optimal control model to examine how lobbying can influence the long-term conversion rate of forests, again not focusing on FT. Using a similar approach, Ollivier (2012) investigated the effect of REDD+ transfer schemes on the long-term land conversion. With the exception of Hartwick et al. (2001), this work has only considered replacement of primary forest with non-forest uses and no possibility of reforestation. None of these studies examine, like we do here, the time point of FT, the speed to which the turning point is reached, and the dynamics of forest cover change as the turning point is approached. Also, previous work also does not examine the importance of land tenure costs and the timing of important policy instruments that can be applied before or after the turning point, or the effects of these instruments on forest cover change. These aspects 
of deforestation are critical, however, in understanding policies that target forest cover loss or ecosystem services, such as REDD and REDD+.

In this paper, we model the transition between primary forest depletion and secondary forest growth in a given economy. Our model highlights the economic features under which a transition is possible and its consequences to climate change and biodiversity. Our approach allows an analysis of the turning point that represents the minimum value of the net forest cover (or highest level of deforestation) in the long run. We also analytically solve for the speed at which an economy reaches the turning point. That allows us to progress on the understanding of the cumulative nature of deforestation. Finally, we examine the role of tenure costs by simulating a REDD+ program that would decrease the costs of securing tenure for plantations to zero. It corresponds to a major investment on property rights, widely recommended by several researchers (Karsenty and Ongolo, 2012). We find that targeting a tenure reform on secondary forests is harmful for the primary native ones.

The following section presents a detailed discussion of the forest transition and highlights the importance of completing the theory by accounting for the two dynamics that actually compose the net forest cover change. The model is developed in section 3, while conditions of a turning point are shown in section 4 together with the study of land uses in the steady state. Section 5 examines the reform in land tenure and its implementation to the results. The last section concludes with a policy discussion.

\section{The Forest Transition theory: towards a more complete frame- work}

The Forest Transition (FT) hypothesis states that the forest stock of a country changes in a predictable way along a development path, following different and distinct phases. Initially, forests are abundant and un-harvested since access to rents is limited. Then, as population growth and infrastructure increase, a major phase of deforestation occurs. Agricultural rents are higher than forest rents on frontier land units, and land is therefore converted to meet food, income and energy demands. Finally, a phase of stagnation and reforestation takes place, and eventually the net deforestation rate turns from positive to either zero or negative. This is the turning point in the FT literature. 
Figure 1: The Forest Transition

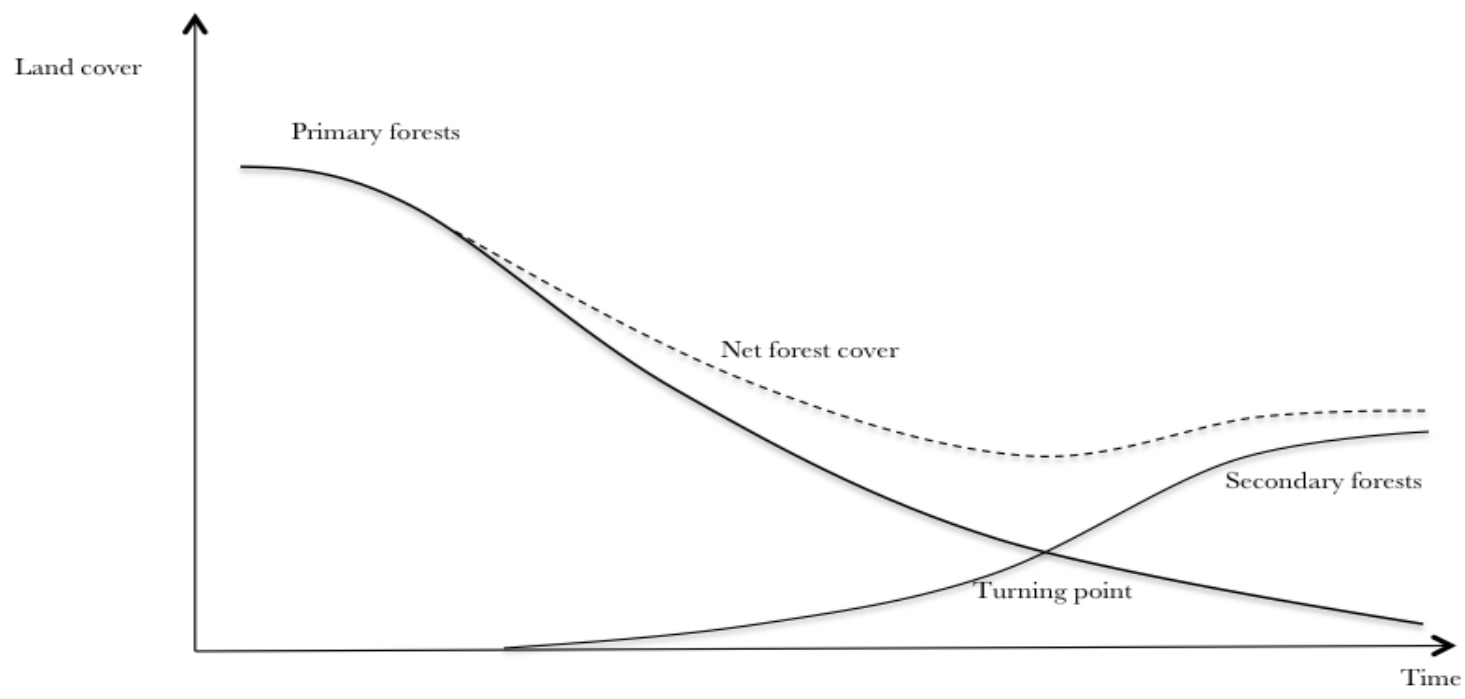

Based on observations of developed nations, Rudel et al. (2005) explained the occurrence of the turning point using either an economic development or a forest scarcity interpretation. The economic development interpretation states that the capital stock formed during agricultural land expansion is reinvested in new, more profitable sectors, that do not require intensive use of forests ${ }^{1}$. Industry-based production increases along with a creation of new urban jobs with higher wages that attract farmers from frontiers to urban areas. Some previously cropped lands therefore return to forest. During this period, governments, who may have become more responsive to ecological and climatic problems, may also implement reforestation programs. Figure 1 illustrates this usual representation of FT and the turning point, along with the expected path of net forest cover through time.

The scarcity interpretation argues that the relative scarcity of land held in forests serves to increase timber prices while leading to potentially high environmental damages due to the lack of forest cover $^{2}$. In order to benefit from the high forest rents and control environmental degradation, large-scale plantations are implemented. The net deforestation rate turns to null or negative, and the turning point occurs. Additionally, globalization can favor the end of deforestation (i.e. a turning point) by trading ecological ideologies, new patterns of demand, or by developing tourism (Lambin and Meyfroidt, 2010). Through a study of several developing countries over 1990-2010,

\footnotetext{
${ }^{1}$ Considering the intensive use of forest includes agricultural activities, since forest and agriculture often compete for the use of land.

${ }^{2}$ For instance, during the 1980s, China has faced desertification, flooding and soil degradation, which had been attributed to deforestation (Mather, 2007).
} 
Wolfersberger, Delacote and Garcia (2013) indeed find that institutional quality also promoted the occurrence of this turning point.

Previous work that considers the dynamics of long term forest conversion is sparse and has focused mainly on the first deforestation phase in Figure 1, that is, before the turning point is reached. The absence of forest plantations and properties of the transitions in discussions of long term deforestation is not consistent with empirical studies showing that, during development, natural old-growth and secondary forests follow two opposite motions that establish an existence of a turning point. Primary forests tend to decrease while secondary forests increase. Grainger (1995) first pointed out this issue, and actually refers to FT as a transition between "two separate national land use processes". Moreover, Mather (2007) and Perz and Skole (2003), respectively, analyzed data from Amazonia and Asia (China, India and Vietnam), claiming that the FT theory required refinements since they found that the net increase of forest cover late in FT was largely composed of plantations. For public policy purposes, Angelsen and Rudel (2013) also highlighted the importance of going beyond the "forest-nonforest dichotomy" within the FT theory. They argued that because of differences in ecosystem services attributed to carbon storage capabilities, considering only net forest cover as a policy target would lead to protection of low carbon landscapes.

The distinction between primary and secondary forests is also a major focus in climate ecology. Luyssaert et al. (2008) argued that old growth forests can store centuries worth of carbon reserves. Regarding carbon dioxide emission, it is therefore more efficient over the short and mid terms to conserve old forests rather than seek to plant new ones. Stephenson et al. (2014) also found that old-growth forests absorb more carbon than new forests despite that growth rates of new forests are higher. Concerning biodiversity, Burley (2002) showed that tropical forests are home to $50 \%$ of the known vertebrates and $60 \%$ of plant species. He argues that forests reestablished on non-forest land as plantations cannot lead to full recovery of all of these species, especially if some agricultural activities took place prior to reforestation. The conclusion from this literature establishes that secondary forests indeed have a lower marginal environmental value than primary ones in terms of both carbon and biodiversity.

It follows that making a distinction between the type of forest (i.e. primary or secondary forests) is necessary since deforestation of primary forests is irreversible in the sense that replacement by secondary forests leads to imperfect substitutes in terms of the ecosystem services that can be produced from any land unit. In our work, we therefore integrate the double dynamics of deforestation and reforestation within the FT framework, and study how it is articulated and what are the implications on development and environment. 


\section{The double dynamics driving the forest cover}

\subsection{The model}

We consider a small open economy with a land endowment normalized to one unit. Initial primary and secondary forest cover is defined by $F_{0}=\bar{F}$ and $S_{0}=\bar{S}$, respectively. Let $f\left(F_{t}\right)$ and $g\left(S_{t}\right)$ be the land rents under the primary $\left(F_{t}\right)$ and the secondary $\left(S_{t}\right)$ forests at any time t. The former includes the public good value associated with an old-growth standing forest (e.g. carbon stock, biodiversity benefits, soil protection, quality of water, etc.) as well as the net income from selective timber harvesting. The latter includes rents from secondary forest plantations, i.e., timber harvesting and public goods value (flows of sequestered carbon, for instance) that are costly to establish. The rent functions for primary and secondary forests differ so as to reflect the imperfect substitutability of the forest stocks, be it in terms of public goods or benefits from harvesting. The rents obtained from agriculture are assumed a function of land available for this use $h\left(1-F_{t}-S_{t}\right)$.

The functions $f(),. g($.$) and h($.$) are assumed to be strictly concave, that is, f^{\prime}\left(F_{t}\right)>0, f^{\prime \prime}\left(F_{t}\right)<$ $\left.0 ; g^{\prime}\left(S_{t}\right)>0, g^{\prime \prime}\left(S_{t}\right)<0\right) ; h^{\prime}\left(1-F_{t}-S_{t}\right)>0$, and $h^{\prime \prime}\left(1-F_{t}-S_{t}\right)<0$. In light of the fact that rents take into consideration both timber and public goods benefits, we consider that $f\left(F_{t}\right), g\left(S_{t}\right)$ and $h\left(1-F_{t}-S_{t}\right)$ reveal the preferences of a representative land user toward different sources of rents.

The dynamics of deforestation and reforestation are represented by the parameters $\left(d_{t}, r_{t} \geq 0\right)$. Deforestation of primary native forests implies $d_{t}>0$ while positive reforestation implies $r_{t}>0$ for any time period. The timber harvested from cleared primary forests is sold at price $p_{F}$, which is kept constant for simplicity without loss, and $C\left(d_{t}\right)$ is the cost of harvesting $d_{t}$ hectares of primary forest at time $t$, with $C^{\prime}\left(d_{t}\right)>0$ and $C^{\prime \prime}\left(d_{t}\right)>0$. Accordingly, $p_{F} \cdot\left(d_{t}\right)-C\left(d_{t}\right)$ represents the profit obtained from clearing primary forest.

Primary forests are considered to be pure open-access resources. The cost of securing tenure of agriculture is considered to be zero. Indeed, in most developing countries, deforestation for agricultural purposes is a way to empower landholders and to avoid expropriation, thus giving these landowners a stronger property right than they would have by holding forest land. For example, Araujo et al. (2009) reported that, in Brazil, landowners clear forests to assert the productive use of land and reduce expropriation risk or increase the ease of obtaining permanent title. In this context, this literature justifies an assumption that plantations entail a land tenure cost of $\Phi_{t}\left(r_{t}\right)$ for $r_{t}$ hectares of planted forest at time $t$, with $\frac{\partial \Phi_{t}}{\partial t}<0, \Phi^{\prime}\left(d_{t}\right)>0$ and $\Phi^{\prime \prime}\left(d_{t}\right)>0$. This land tenure 
cost represents the effort devoted to protect the forest investment, which is costlier in countries with low enforcement. Empirical justification for these costs is discussed in Bohn and Deacon (2000).

The representative land user agent chooses the levels of deforestation and reforestation that maximize his welfare, that is:

$$
\max _{d_{t}, r_{t}} W\left(d_{t}, r_{t}\right)=\int_{0}^{T}\left[f\left(F_{t}\right)+g\left(S_{t}\right)+h\left(1-F_{t}-S_{t}\right)+p_{F} d_{t}-C\left(d_{t}\right)-\Phi_{t}\left(r_{t}\right)\right] e^{-\delta t} d t
$$

Subject to the following constraints reflecting our discussion above:

$$
\begin{aligned}
& \dot{F}_{t}=-d_{t}, \\
& \dot{S}_{t}=r_{t}, \\
& F_{0}=\bar{F}, \\
& S_{0}=\bar{S}, \text { and } \\
& d_{t} \geq 0 ; r_{t} \geq 0 \quad \forall t \in[0, T] .
\end{aligned}
$$

From (1), the current value of the Hamiltonian for the land user's problem is:

$$
H=f\left(F_{t}\right)+g\left(S_{t}\right)+h\left(1-F_{t}-S_{t}\right)+p_{F} \cdot d_{t}-C\left(d_{t}\right)-\lambda_{t} d_{t}+\mu_{t} r_{t}-\Phi_{t}\left(r_{t}\right)
$$

where $\lambda_{t}$ and $\mu_{t}$ respectively denote the co-state variables associated with deforestation $d_{t}$ and reforestation $r_{t}$. Applying Pontryagin's Maximum Principle enables us to obtain the necessary conditions for the optimal paths of deforestation and reforestation. The first-order conditions with respect to $d_{t}$ and $r_{t}$, are:

$$
\begin{aligned}
& H_{d_{t}}=p_{F}-C^{\prime}\left(d_{t}\right)-\lambda_{t}=0, \text { and } \\
& H_{r_{t}}=-\Phi_{t}^{\prime}\left(r_{t}\right)+\mu_{t}=0 .
\end{aligned}
$$

From (3), we observe that if $p_{F}-C^{\prime}\left(d_{t}\right)<\lambda_{t}$, primary forests conversion will not occur. In this case, the marginal increase in rents from harvesting is lower than the shadow price of the in situ forest stock at time $t$. From (4), reforestation will not occur if the shadow value of secondary forests in situ, $\mu_{t}$, is lower than tenure costs at the margin, $\Phi_{t}^{\prime}\left(r_{t}\right)$. Indeed, secondary forests are established only when their net rent becomes high enough. Given that we assume a decreasing land tenure cost over time, as an economy develops, secondary forests start growing only when the tenure cost is below a certain threshold. This is consistent with the empirical results of Bohn and Deacon (2000), who show that countries with more developed enforcement and less political 
instability, along with lower probability of illegal logging or expropriation, are consistent with lower plantation investment costs.

The dynamics of the co-state variables are given by:

$$
\begin{aligned}
& \dot{\lambda_{t}}=\delta \lambda_{t}-f^{\prime}\left(F_{t}\right)+h^{\prime}\left(1-F_{t}-S_{t}\right), \text { and } \\
& \dot{\mu}_{t}=\delta \mu_{t}-g^{\prime}\left(S_{t}\right)+h^{\prime}\left(1-F_{t}-S_{t}\right) .
\end{aligned}
$$

The transversality conditions for this model are:

$$
\begin{aligned}
\lim _{t \rightarrow \infty} e^{-\delta t} \lambda_{t} F_{t} & =0, \text { and } \\
\lim _{t \rightarrow \infty} e^{-\delta t} \mu_{t} S_{t} & =0 .
\end{aligned}
$$

From (5), the shadow price of a hectare of primary forest converted to agriculture increases with the marginal net benefit from favoring agriculture at the expense of sustainable primary forest management, $h^{\prime}\left(1-F_{t}-S_{t}\right)-f^{\prime}\left(F_{t}\right)$. It follows that this shadow price decreases as primary forests become relatively more scarce. Deforestation thus clearly decreases over time and primary forests disappear in an irreversible manner, which is consistent with the forest scarcity path interpretation of the FT theory. Moreover, substituting (3) into (5) indicates that deforestation decreases over time if the marginal return to forest conversion decreases.

In contrast, (6) states that the marginal cost of converting an additional land unit of agriculture into secondary forests increases with the marginal net benefit of agriculture relative to sustainable secondary forests management, $h^{\prime}\left(1-F_{t}-S_{t}\right)-g^{\prime}\left(S_{t}\right)$. Again, using (4) into (6) indicates that reforestation increases over time if the marginal land tenure costs decrease.

The optimal paths of deforestation and reforestation from (3) and (4) can now be obtained as:

$$
\begin{aligned}
-C^{\prime \prime}\left(d_{t}\right) \dot{d}_{t} & =h^{\prime}\left(1-F_{t}-S_{t}\right)-f^{\prime}\left(F_{t}\right)+\delta\left[p_{F}-C^{\prime}\left(d_{t}\right)\right], \text { and } \\
\Phi_{t}^{\prime \prime}\left(r_{t}\right) \dot{r_{t}} & =h^{\prime}\left(1-F_{t}-S_{t}\right)-g^{\prime}\left(S_{t}\right)+\delta \Phi_{t}^{\prime}\left(r_{t}\right) .
\end{aligned}
$$

The time path of deforestation depends on the rate of change in relative rents to agricultural clearing net of the loss in public goods values from cleared primary forests (first two terms on the right hand side of (9), in addition to the interest cost of not clearing land in terms of net rents to clearing primary forests (last term on the right hand side of (9)). Equation (10) shows that the rate of reforestation is determined as a condition that equates the marginal benefits of secondary forest revenues (second term on the right-hand side) net of marginal benefits of cleared land used instead for agriculture (first term on the right-hand side) plus the marginal land tenure costs (third term on the right-hand side). The point in time where these paths cross, which is unique owing 
to convexity and concavity assumptions - and is investigated later -, clearly depends on changes in rents to all land uses over time as well as the important land tenure costs that must be paid to secure secondary forests.

\subsection{Numerical assumptions and scenarios}

Our results are illustrated by numerical simulations. A key part of our numerical results is the assumption concerning the form of the welfare function that makes up the objective functional in our dynamic optimization problem above. We voluntarily choose scenarios of contrasted preferences in order to emphasize their consequences on FT. The simulations should therefore not be considered for their numerical results, but for the qualitative and illustrative contents they provide. A convenient explicit form of our welfare function is:

$$
\begin{array}{r}
W\left(d_{t}, r_{t}\right)=\int_{0}^{T}\left[\alpha \ln F_{t}+\beta \ln S_{t}+(1-\alpha-\beta) \ln \left(100-F_{t}-S_{t}\right)+p_{F} \cdot d_{t}-\frac{1}{2} \cdot\left(d_{t}\right)^{2}\right. \\
\left.-\lambda_{t} d_{t}-\frac{1}{2} \cdot\left(r_{t}\right)^{2}+\mu_{t} r_{t}\right] e^{-\delta t} d t .
\end{array}
$$

The parameter $\alpha$ in (11) is a preference indicator for holding and not deforesting primary forests over time, while $\beta$ is a preference parameter for establishing secondary forests; thus, the preference for clearing land for agriculture in a relative sense is: $1-\alpha-\beta$. By assumption: $0<\alpha$ and $\beta<1$. The cost functions $C($.$) and \Phi_{t}($.$) , respectively the costs of deforesting and securing the$ reforested lands, are convex and have the same form as in Hartwick et al. (2001): $C\left(d_{t}\right)=\frac{1}{2} \cdot\left(d_{t}\right)^{2}$ and $\Phi\left(r_{t}\right)=\frac{1}{2} \cdot\left(r_{t}\right)^{2}$.

Table 1 provides the parameters that differentiate the scenarios. Scenario 1 is the benchmark scenario, where the representative land user agent gives more weight to agriculture and is indifferent between primary and secondary forests. This is the usual way development proceeds in a country with forests. Other scenarios are used to examine the various drivers of the model.

Notice that the variations of land tenure costs (scenarios 4 and 5) are built on the benchmark case (scenario 1). Indeed, a larger preference for agriculture, consistent with a lower $\alpha$ and $\beta$, is more prevalent in a developing economy, whose tenure is costly to secure.

\section{Analyzing the patterns of the forest transition}

We now examine the resources stock under different features of our model: first, the speed of FT is analyzed; second, the size of the forest resources stock is considered when deforestation ceases, 
i.e., at the turning point; third, the forest composition is analyzed when the economy reaches a steady state. Finally the influence of marginal rents and tenure costs on stock are also examined. As we will show, these features are all necessary to completely describe FT.

\subsection{Speed of deforestation and reforestation in the transition}

From (9), the speed of deforestation from primary forests decreases with the rents from primary forests, increases with the preferences for agriculture (or agricultural rent), and increases with the net marginal benefit of forest conversion. Equation (10) shows that the speed of reforestation increases with preferences for secondary forests (or secondary forests rent), decreases with preferences for agriculture, and decreases with marginal land tenure costs. Figure 2 illustrates these results.

Referring to the first scenario in the figure, the agricultural area surpasses $50 \%$ of the total land area by 100 time-periods. The turning point occurs just before time-period 150. While the initial stock of primary forest covers $80 \%$ of total land, it ends up at a level of only $20 \%$. In scenario 2 and 3 , the relative preference is given to forests. In scenario 2 , the highest rents are attributed to primary forests while scenario 3 shows a situation where relative rents are higher in secondary forests. Unlike scenario 1, we note that deforestation proceeds more slowly when rents generally favor forests. We also observe that scenario 2 leads to a longer transition than either scenario 1 and 3 , but ultimately results in a preservation of more primary native forest cover.

\subsection{Analyzing of the turning point}

As described in Section 2, the turning point is of particular importance in the FT theory. At this point, net forest cover no longer decreases and reforestation compensates for deforestation. Two

Table 1: Simulation scenarios

\begin{tabular}{|lccccc|}
\hline Description & Scenario & $\alpha$ & $\beta$ & $(1-\alpha-\beta)$ & Land tenure costs \\
\hline Pref. for agriculture & 1 & 0.3 & 0.3 & 0.4 & $\frac{1}{2}\left(r_{t}\right)^{2}$ \\
Pref. for prim. forests & 2 & 0.4 & 0.3 & 0.3 & $\frac{1}{2}\left(r_{t}\right)^{2}$ \\
Pref. for sec. forests & 3 & 0.3 & 0.4 & 0.3 & $\frac{1}{2}\left(r_{t}\right)^{2}$ \\
Increasing tenure costs & 4 & 0.3 & 0.3 & 0.4 & $\left(r_{t}\right)^{2}$ \\
Decreasing tenure costs & 5 & 0.3 & 0.3 & 0.4 & $\frac{1}{4}\left(r_{t}\right)^{2}$ \\
\hline
\end{tabular}


Figure 2: Variation in land uses under different preferences
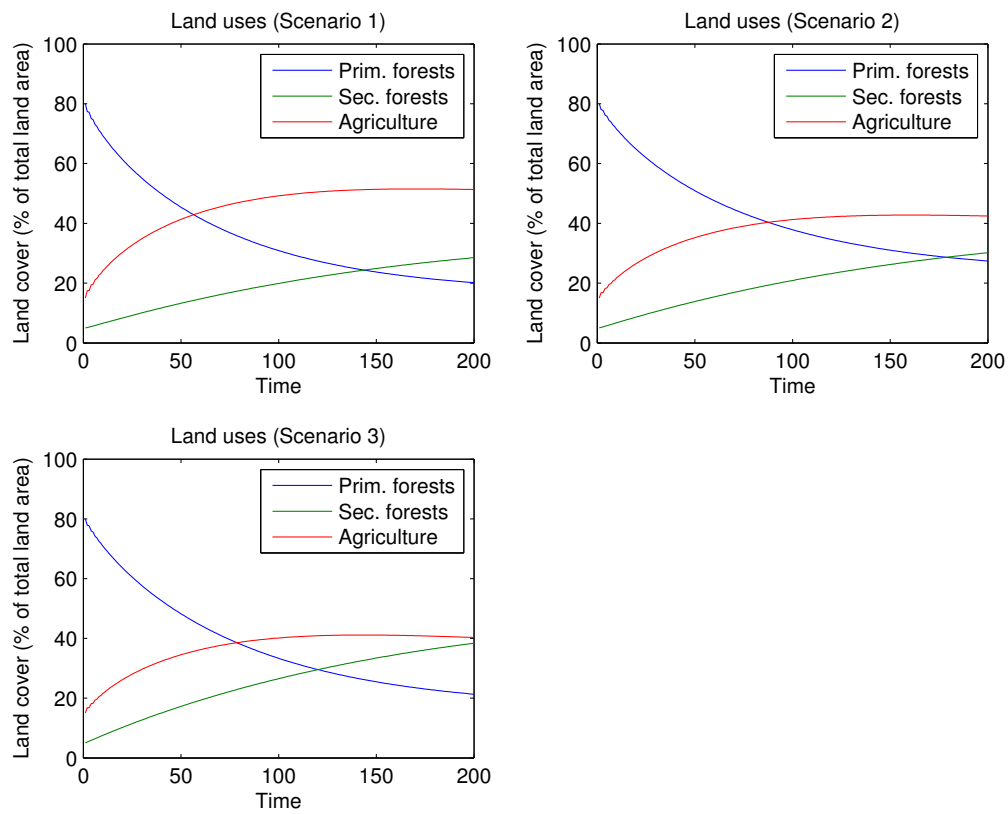

characteristics of the turning point have to be considered. The first is forest cover at the turning point which gives an indication of the cumulative nature of deforestation during the development phase. Second, the time at which the turning point occurs is important as it indicates the length of the net deforestation (deforestation minus reforestation) phase.

The turning point takes place when the gain in secondary forest offsets the loss of primary forests, i.e.

$$
\dot{d}_{t}=\dot{r}_{t}
$$

Using this expression with (5) and (6) yields:

$$
f^{\prime}\left(F_{t}\right)+g^{\prime}\left(S_{t}\right)=2 h^{\prime}\left(1-F_{t}-S_{t}\right)+\delta\left[p_{F}-C^{\prime}\left(d_{t}\right)+\Phi_{t}^{\prime}\left(r_{t}\right)\right]
$$

Equation (13) shows that the turning point between primary and secondary forests occurs when the double marginal return from agriculture equals the total marginal rents from all forest cover, minus the discounted profit from primary forest timber sale and the marginal cost of land tenure. ${ }^{3}$ This result is consistent with the forest scarcity path interpretation of the FT theory. Indeed, we see that the turning point occurs when the marginal value associated with forests equals that of converting it.

\footnotetext{
${ }^{3}$ Notice that our result holds for $\Phi_{t}^{\prime \prime}\left(r_{t}\right)=C^{\prime \prime}\left(d_{t}\right)=1$, which is in accordance with our explicit program.
} 
Hence, we can deduce that the forest stock at the turning point is higher when preferences and rents for primary and secondary forests are higher, and lower when timber price or preferences for agriculture are higher. This result is confirmed by our simulations. It is straightforward to see from scenario 2 that the turning point occurs at a lower forest cover when preferences for agriculture are stronger.

\subsection{Role of land use and tenure costs to the length of the transition}

In assessing transition length, our analysis uncovers two important questions: land-user preferences and land tenure costs. Another interesting piece of information comes from revisiting the length of FT discussed in section 3.2. From equation (12), ceteris paribus, a slower speed of deforestation indicates a longer FT, in the sense that it takes longer for the deforestation rate $d_{t}$ to equal that of reforestation $r_{t}$. The same type of reasoning can be done with reforestation: a slower speed of reforestation also indicates a longer FT.

We can therefore reason that the length of FT increases with preferences for primary forests and decreases with the marginal benefit from primary forest conversion, since they decrease the speed of deforestation. Further, the FT length decreases with preferences for secondary forests and increases with marginal land tenure costs, which increase the speed of reforestation. Finally, the FT length may either increase or decrease with preferences for agriculture, since this increases both the speed of deforestation and decreases the speed of reforestation.

This result is visible in our simulations. Scenario 2 results in a lower rate of deforestation. In the same manner, when preferences for secondary forests are low, the reforestation rates are lower. Finally, when the preferences for agriculture are low, they tend to decrease the deforestation rate and to increase the reforestation rate. The junction of these three effects produces a longer FT.

In contrast, scenario 3 presents a relatively short FT. Here, higher preferences for secondary forests enhance the speed of reforestation. Conversely, low preferences for primary forests increase the speed of deforestation. Lower agricultural preferences increase the reforestation rate and decrease the deforestation rate. In sum, a shorter FT is observed.

These results provide interesting insights into the cumulative nature of deforestation. Indeed, when preferences for primary forests are higher, the net deforestation phase lasts longer, yet the cumulative amount of deforestation will be smaller. Thus, having positive net rates of deforestation is not necessarily critical for a country: it may simply mean that the FT phase will be longer, but with lower cumulative deforestation. In the same manner, high deforestation rates may suggest that FT will appear more rapidly and potentially end with smaller cumulative deforestation. These 
are key results and suggest that the timing of policy aimed at reducing deforestation is much more complicated than previously thought.

The magnitude of tenure cost also influences the length of transition. Equation (13) and Figure 3 illustrate this.

Figure 3: Change in land tenure costs
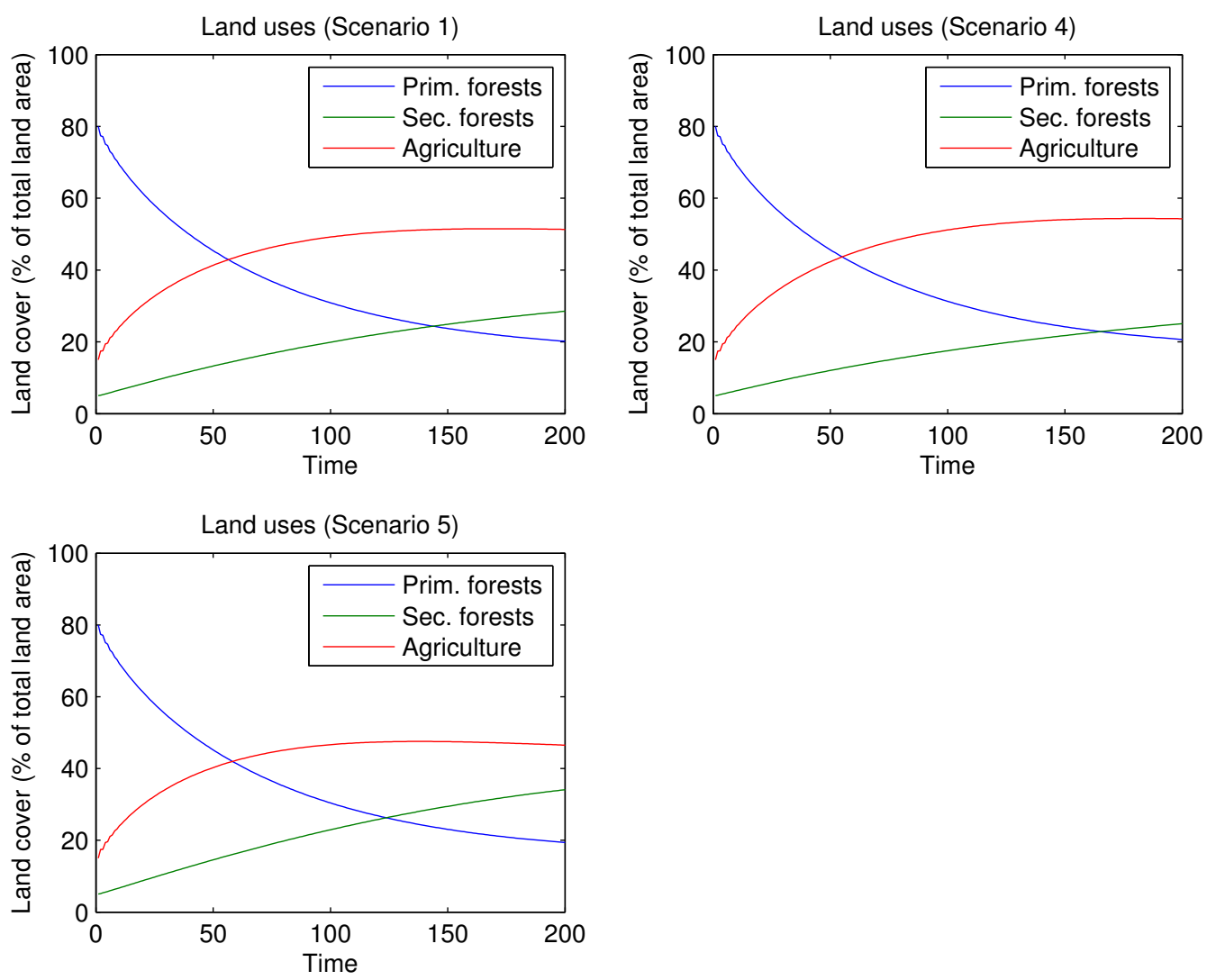

The occurrence of the turning point is clearly affected by the land tenure costs. An increase of these costs (scenario 4) delays the turnaround point in forest cover relative to the reference case (scenario 1). The turning point occurs around 20 time-periods later. On the contrary, not only does a decrease of these costs (scenario 5) significantly accelerates the occurrence of the turning point, but it appears at a time-period with a higher total forest cover. This result is particularly relevant for public policies such as REDD+. Obviously, one way to promote transitions in developing countries is to reinforce property rights and political stability in order to decrease the tenure costs. Data provided by FAO and World Bank support this, as illustrated by Figure 4 . 
Figure 4: Reforestation and tenure costs in 14 countries (year 2000)

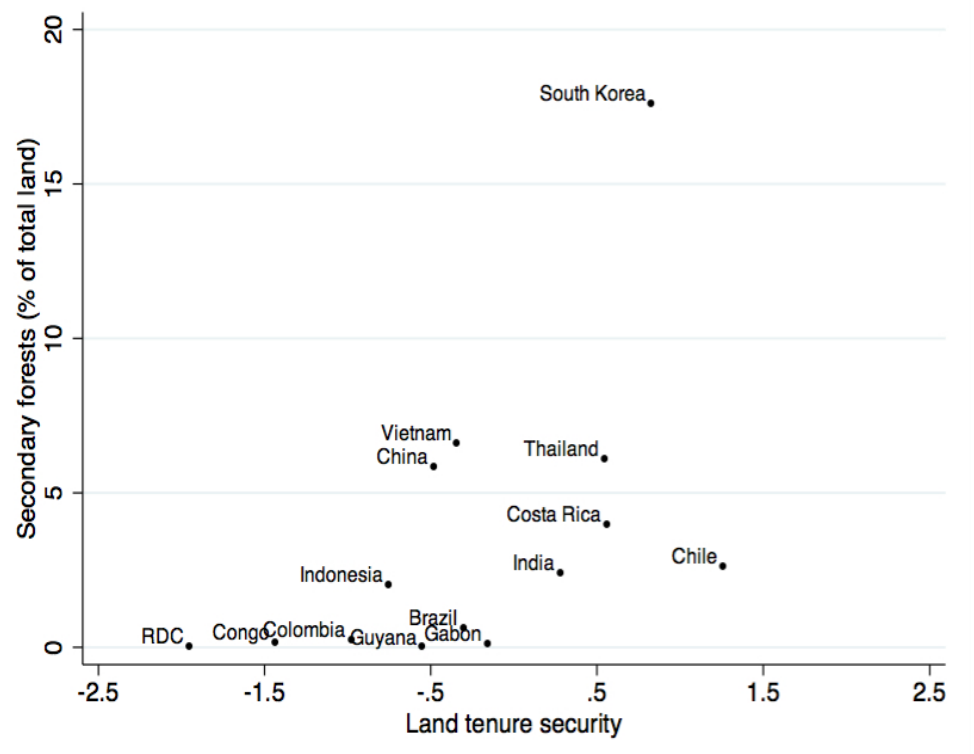

Data sources: FAO and World Bank

Tenure security is here measured by the "Rule of Law" variable from the World Bank, that "reflects perceptions of the extent to which agents have confidence in and abide by the rules of society, and in particular the quality of contract enforcement, property rights, the police, and the courts, as well as the likelihood of crime and violence". It varies within a range of $-2,5$ to 2,5 . A high score signifies low tenure costs. It is obvious that when the tenure security is very low, like in Congo, Colombia or Indonesia, the share of secondary forests is low as well. Conversely, better ranked countries such as Costa Rica, Thailand or South Korea are found to have practiced more reforestation. These observations are consistent with what our new model shows. Note that one must be careful when analyzing this figure since the development is also incorporated. For example, in the Democratic Republic of Congo (RDC) the tenure security and the share of secondary forests are both low. However, it is important to keep in mind that such a country has not yet started its major deforestation phase. This may also explain its low share of secondary forests.

In all, and from a long term perspective, our model establishes that focusing only on deforestation rates may clearly be misleading in terms of predicting the final result of cumulative deforestation. We now provide an analysis of the steady states. 


\subsection{Steady state analysis}

Studying the steady state is of particular interest since it is likely that a given country reaches this condition after development. For example, France experienced its turning point during the $18^{\text {th }}$ century, while the US reached it in the early 1900s, and the forest cover of both countries can therefore be considered as stationary.

Before the stationary point is reached, clearing an additional hectare of primary forests provides $h^{\prime}\left(1-F_{t}-S_{t}\right)+\delta \lambda_{t}$, while sustainable primary forests management gives $f^{\prime}\left(F_{t}\right)+\dot{\lambda_{t}}$. Likewise, an additional hectare of secondary forests yields $g^{\prime}\left(S_{t}\right)+\dot{\mu}_{t}$ while agriculture gives $h^{\prime}\left(1-F_{t}-S_{t}\right)+\delta \mu_{t}$.

In the steady state $\dot{F}_{t}=\dot{\lambda}_{t}=0$ and $\dot{S}_{t}=\dot{\mu}_{t}=0$. We find in this case that the marginal benefit from converting a hectare of natural old-growth forest $\delta \cdot p_{F}+h^{\prime}\left(1-F_{\infty}-S_{\infty}\right)$ equals the marginal return from sustainable primary forest management $f^{\prime}\left(F_{\infty}\right)$.

Concerning the dynamics of secondary forests, the steady state can be written as the equality of the marginal rents from a hectare of agriculture $h^{\prime}\left(1-F_{\infty}-S_{\infty}\right)$ and the marginal rents of a hectare of plantations $g^{\prime}\left(S_{\infty}\right)$. The representative agent is then indifferent between allocating an additional hectare of land either to agriculture or to the secondary forests.

Equalizing the steady states of the two types of forests by the marginal return from agriculture $h^{\prime}\left(1-F_{\infty}-S_{\infty}\right)$ yields:

$$
f^{\prime}\left(F_{\infty}\right)-\delta \cdot p_{F}=g^{\prime}\left(S_{\infty}\right)
$$

This result shows that, in the steady state, the marginal benefit from secondary forests equals that of primary forests minus the discounted sale price of timber obtained from clearing primary forests. This can be explained by the delay between the period of planting and realization of high ecosystem service benefits. This last equation implicitly describes the tradeoff between primary and secondary forests. It follows that the forest composition differs when preferences lean toward primary or secondary forests. As a result, total forest cover in the steady state is composed of both primary and secondary forests that depends on the relative preferences for primary and secondary forests. Figure 8, in appendix, confirms this effect. Costa Rica and Vietnam which just passed the turning point, have a significantly different forest composition. In Vietnam, almost no primary forests were saved during the transition. Since this type of forest can be viewed as a nonrenewable resource, its amount can only be equal or lower in the steady state.

When primary forests are preferred, such as in scenario 2 and 3, primary forests represent a larger share of the forest cover in the long run. This result clearly indicates the validity and the importance of separately considering the dynamics of deforestation and reforestation. Indeed, 
when considering preferences for forests without distinguishing between their types, one would miss this composition effect. We can also argue that, despite similar total forest covers, Scenario 2 is preferable in terms of biodiversity and carbon stocks, while Scenario 3 better performs in terms of timber harvesting.

\section{Public policies: an application to institutional reforms}

\subsection{Land tenure costs reduction}

Consider the implication of a drastic decrease in land tenure costs. This type of reduction may come from the first phase of REDD+ implementation where strengthening tenure security is frequently mentioned as a key element before carbon redistribution. Moreover, previous results (Araujo et al. (2009); Bohn and Deacon (2000); Wolfersberger et al. (2013)) confirm that public policies should be targeted toward improving land institutions in order to retard deforestation. Karsenty and Ongolo (2012) further suggest that REDD+ architecture should focus on property rights and institutional quality before any policy application of the theory of incentives. For this reason, we focus on the tenure costs in this application. We present a "Business As Usual" (BAU) scenario, which is our benchmark case (scenario 1), and two scenarios of public policies. Table 2 details the policy programs we examine.

Table 2: Public policy scenarios

\begin{tabular}{l|ccccc} 
Description & Scenario & Land tenure costs & Interval & Land tenure costs & Interval \\
\hline BAU & 1 & $\frac{1}{2}\left(r_{t}\right)^{2}$ & {$[0,200]$} & - & - \\
Program 1 & 6 & $\frac{1}{2}\left(r_{t}\right)^{2}$ & {$[0,70[$} & 0 & {$[70,200]$} \\
Program 2 & 7 & $\frac{1}{2}\left(r_{t}\right)^{2}$ & {$[0,10[$} & 0 & {$[10,200]$}
\end{tabular}

For comparison purposes, preferences are assumed equal for the three scenarios, based on scenario $1(\alpha=\beta=0.3$ and $(1-\alpha-\beta)=0.4)$. The first program (scenario 6$)$ is implemented halfway to the transition and corresponds to countries such as Brazil or Indonesia. The second program (scenario 7) is implemented earlier during the transition, and it corresponds to the less deforested countries such as Congo or Gabon. The representative land user agent is assumed to face zero tenure costs under application of one of the programs (1 or 2). Results are given in table $3 .{ }^{4}$ It is

\footnotetext{
${ }^{4}$ Land uses corresponding to these results are given in appendix A, Figure 7.
} 
important to note here that numerical results have no signification per se (in terms of per hectares values for instance), but they are useful to give an idea on the qualitative interpretation of our model.

Table 3: Numerical results of public policy on land tenure costs

\begin{tabular}{l|l|l|l} 
& BAU & Program 1 & Program 2 \\
\hline$F_{t=200}$ & 20.2 & 20.0 & 19.9 \\
$S_{t=200}$ & 28.5 & 29.9 & 30.1 \\
Turning point time-period & 144 & 140 & 136 \\
$\sum_{t}\left(F_{t}-F_{t}^{B A U}\right)$ & - & -11.9 & -31.0 \\
$\sum_{t}\left(S_{t}-S_{t}^{B A U}\right)$ & - & 121.6 & 199.7
\end{tabular}

Adding the shares of both types of forest at the end of FT $(t=200)$, we find that programs 1 and 2 allow a country to preserve more total forest cover during development than in the BAU case. This shows the effectiveness of the public policy. Also, when any of the programs is implemented, net forest depletion halts earlier than in the BAU situation (i.e. the turning point occurs earlier). However, two effects have to be distinguished. First, the policy has a direct effect of boosting reforestation. Since it is implemented at time-period 10, scenario 7 always provides the best output in terms of reforestation. This therefore ends net emissions from forestry earlier than in the benchmark BAU scenario. It is interesting to note the cumulative nature of reforestation here (last line of table 3 ). In terms of carbon balance, scenario 7 is preferable to scenario 6 , as the public policy of reforestation is set up earlier, which is more valuable in terms of carbon benefit. This result underlines the needs to implement forest policies earlier during the transition, in order to benefit from this sequestration effect.

Second, the policy has an indirect effect on deforestation. Indeed, the more aggressive is the policy reform to tenure costs for reforestation (Program $2>$ Program $1>$ Benchmark case), the lower is the amount of primary forests at the end of the transition $(t=200)$. Also, the difference between the total area of primary forests with and without the program $\sum_{t}\left(F_{t}-F_{t}^{B A U}\right)$ shows a loss of 11.9 and 31 in programs 1 and 2, respectively. These losses correspond to carbon releases due to deforestation. Then, under our assumptions, a public policy favoring reforestation also promotes deforestation of primary native forests. It can be explained by the fact that, in the model, the reforestation takes place on agricultural land. This corresponds to empirical observations. Given 
this indirect effect of the public policy, one must be careful when designing a REDD+ strategy, since it can be harmful for primary native forests that have the highest ecological value.

Finally, Figure 5 presents the welfare yielded by the different programs.

Figure 5: Variation of Welfare under different REDD+ programs on tenure costs

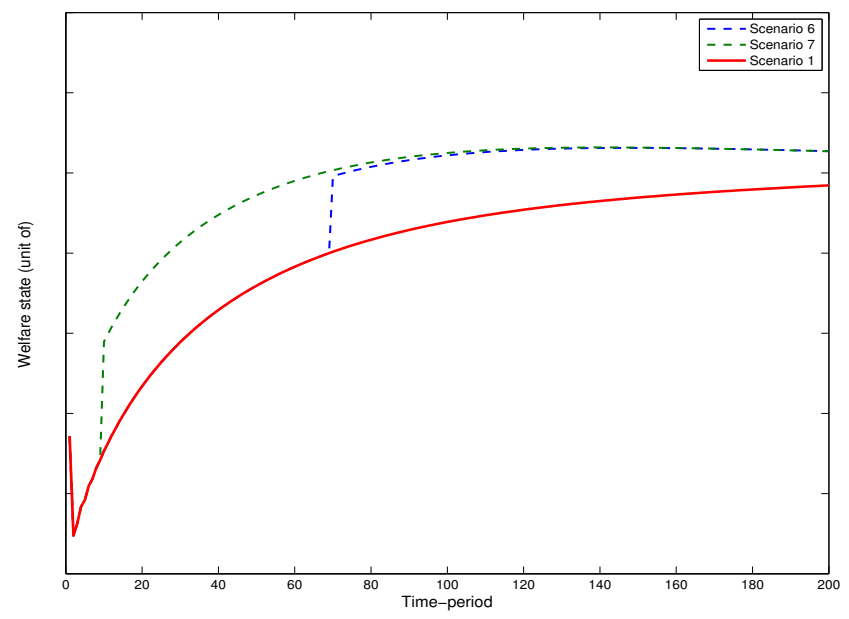

Not surprisingly, implementing a REDD+ program increases the welfare compared to "nonacting" (scenario 1). The earlier the public policy is implemented, the higher is the welfare. This makes sense since a financial cost is removed, and we can then observe a peak at this moment (timeperiods 10 and 70). It follows that rents from forestry provide a higher net benefit. Assuming that the implementation of the program is costless for the representative land user agent ${ }^{5}$, the area between the red curve and the blue and green ones represents a social cost of not protecting the forests. The later the program is implemented, the higher this cost is.

\subsection{Increasing the costs of deforestation}

Now consider the implication of an increase in the cost of primary forest harvesting. We compare our BAU scenario with a scenario where deforestation costs are double. Table 4 details the policy program we examine.

\footnotetext{
${ }^{5}$ This assumption is enough realistic since REDD+ is overall a mechanism financed by North countries.
} 
Table 4: Public policy

\begin{tabular}{l|ccccc} 
Description & Scenario & Deforestation costs & Interval & Deforestation costs & Interval \\
\hline BAU & 1 & $\frac{1}{2}\left(d_{t}\right)^{2}$ & {$[0,200]$} & - & - \\
Program 3 & 8 & $\frac{1}{2}\left(d_{t}\right)^{2}$ & {$[0,10[$} & $\left(d_{t}\right)^{2}$ & {$[10,200]$}
\end{tabular}

For comparison purposes, we maintain the preferences unchanged $(\alpha=\beta=0.3$ and $(1-\alpha-\beta)=$ 0.4). The reform targeting primary forest is implemented early during the transition, at time-period 10. This is in line with recommendations from Angelsen and Rudel (2013) for countries in the core forest stage of forest transition. The increase in the costs of primary forest harvesting may correspond to different possible actions, such as the implementation of protected areas, the use of monitoring/measuring, reporting, and verifying (MRV) systems or an increase of decentralization associated with a higher control of corruption. It may also globally correspond to a reduction in access to primary native forests, for example by framing the construction of new roads. Results are given in table 5.

Table 5: Numerical results of public policy on deforestation costs

\begin{tabular}{l|l|l} 
& BAU & Program 3 \\
\hline$F_{t=200}$ & 20.2 & 21.2 \\
$S_{t=200}$ & 28.5 & 28.1 \\
Turning point time-period & 144 & 157 \\
$\sum_{t}\left(F_{t}-F_{t}^{B A U}\right)$ & - & 378.9 \\
$\sum_{t}\left(S_{t}-S_{t}^{B A U}\right)$ & - & -63.2
\end{tabular}

Again, the simulations allow us to identify both direct and indirect effects. ${ }^{6}$ Indeed, the rise in deforestation costs increases the stock of primary native forest. We find that compared to the BAS scenario, 378.9 units of primary native forest cover are saved over the total transition. The indirect effect logically affects the stock of secondary forest, with a loss of 63.2 units. It confirms that a land use competition exists between the two forest types. It is important to consider it for REDD+, in order to reach the most ecologically valuable outputs, depending on the country's

\footnotetext{
${ }^{6}$ It is important to keep in mind that despite the presence of an indirect effect, all scenarios of public policies lead to an increase in total forest area (primary and secondary forests taken together), and a decrease of total agricultural area, in comparison with BAS scenario. Figure 7 in appendix illustrates it.
} 
context. Intuitively, in countries such as Guyana or the Democratic Republic of Congo, with a significant share of primary forest remaining, the REDD+ national strategy must target the deforestation costs. Privileging the secondary forest through a tenure cost reform would here be harmful for old-growth natural forest that contains the largest quantity of biodiversity and carbon stock. On the contrary, in countries such as Vietnam, where only a low quantity of primary native forests remains, ${ }^{7}$ targeting deforestation costs would be ineffective. In those countries, a policy of land tenure costs reduction seems more appropriate.

\section{Concluding remarks}

In this paper, we analyze the double dynamics of deforestation and reforestation that describe the forest transition. Primary native forests and secondary forests have different climate and ecological characteristics. It is therefore important to go beyond the usual "forest vs. agriculture" framework when studying land use in developing countries. It is equally important to consider the imperfect substitutability between the two types of forests. Four important results are revealed by our analysis.

The speed of deforestation and reforestation can be analyzed through the evolution of marginal rents of the different types of forest relative to those of agriculture. The speed of deforestation is also determined by the marginal benefit of land conversion, while the speed of reforestation decreases with the land tenure costs. The turning point occurs when the marginal rents from the total forest cover in situ equal those of the agricultural and commercial uses.

We highlighted a composition effect of forest cover in the steady state. Indeed, our model makes it possible to distinguish between primary and secondary forests. Given their different properties in terms of biodiversity and carbon storage, this result is very important. We showed that the composition of the forest stock in the steady state depends critically on the decision maker's preferences. With a higher preference for primary forests, our results suggest that more biodiversity will be preserved over development and larger quantities of carbon will be stored.

Our model also allows a study of the lengths of forest transitions. In particular, we find that the country's net deforestation rates should be cautiously analyzed. Even if the turning point occurs further in time, it can be characterized by higher ecological benefits and less cumulative deforestation. Likewise, we find that net deforestation ends earlier in time when a country's preferences

\footnotetext{
${ }^{7}$ Please, see appendix B for details on forest composition in a selected sample of developing countries.
} 
are moving toward more secondary forests. Data from FAO on secondary forests confirms these findings (see Figure 6).

Figure 6: Secondary forests in 14 countries (year 2000)

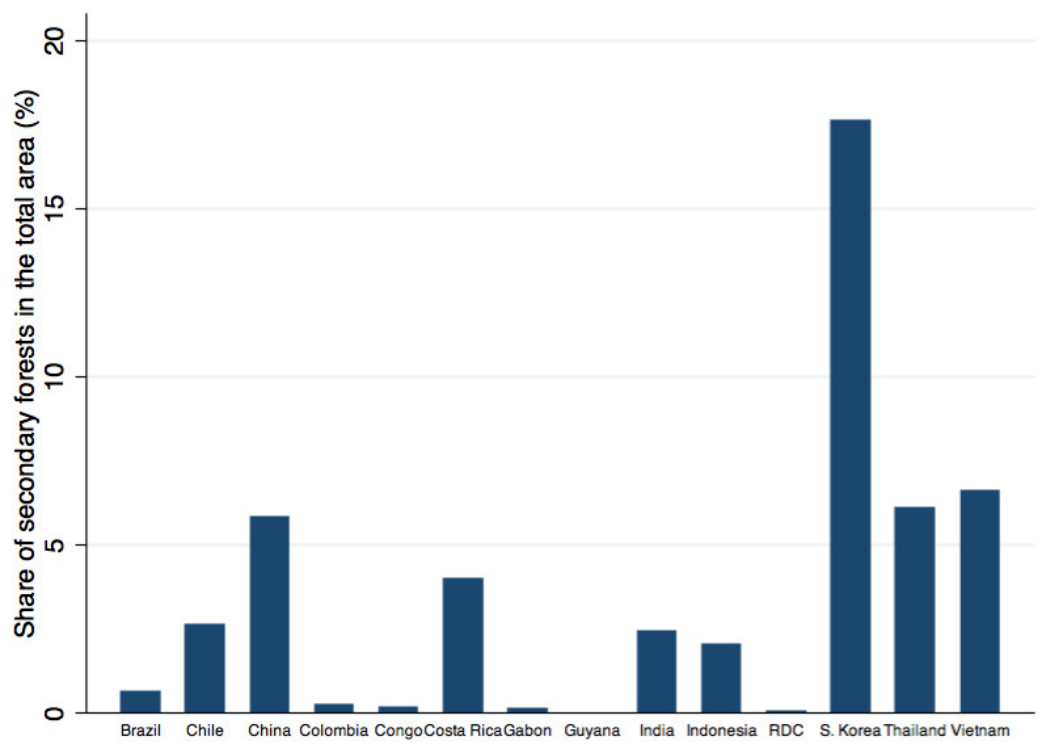

Data source: FAO

Countries experiencing a turning point are also the ones where the share of reforestation is important. The examples of China, Costa Rica, South Korea and Vietnam highlight this effect. In addition, some countries considered as being close to the turning point, (e.g. Chile, Thailand) have larger shares of secondary forests than countries identified as distant from the turning point, e.g. Congo, Gabon, Guyana or Democratic Republic of Congo.

These empirical evidence reinforce our findings about the application of REDD +. By identifying direct and indirect effects, we show that the priority, in countries distant from the turning point, is to implement programs that increase the deforestation cost of primary native forests. These programs can be the settlement of protected areas, a system of certification etc., which may allow to preserve more primary native forests over the total transition. It is particularly relevant and urgent in countries like Paraguay, where $78 \%$ of the Intact Forest Landscapes were degraded since 2000, as reported by World Resource Institute. On the contrary, in countries close from the turning point, the REDD+ strategy should be different. These countries should aim to raise reforestation, like for instance, the "Sloping Land Conservation Program" in effect in China since the 1980's (Bennett, 2008). In line with our findings, despite an indirect effect, public policies in these countries should 
consist in tenure reforms to promote the growth of secondary forests, since the amount of primary native forests remaining may be very low.

In conclusion, from a long-term perspective, we show that the net deforestation rates can be misleading. Accordingly, public policies should instead consider different types of forests at stake and better take into account the real motives behind the preferences for the forest cover conservation. According to our findings, the preferences of policy makers ought to be taken into account. Likewise, reducing the costs of tenure security should be undertaken.

\section{Aknowledgement}

The UMR 356 Economie Forestière is supported by a grant overseen by the French National Research Agency (ANR) as part of the "Investissements d'Avenir" program (ANR-11-LABX-0002-01, Lab of Excellence ARBRE). The authors would like to thank the attendees of the Laboratory of Forest Economics seminar (Nancy, France, 2014), the Climate Economics Chair seminar (Paris, France, 2014), the Paris-Ouest University seminar (Paris, France, 2014), the World Congress of Environmental and Resource Economists (Istanbul, Turkey, 2014), and the congress of the French Association of Environmental and Resource Economists (Montpellier, France, 2014), for their comments and feedbacks on this work. Authors also thank Eric Nazindigouba Kere. 


\section{Appendix A: Numerical results on land uses}

Figure 7: Land uses change under different scenarios
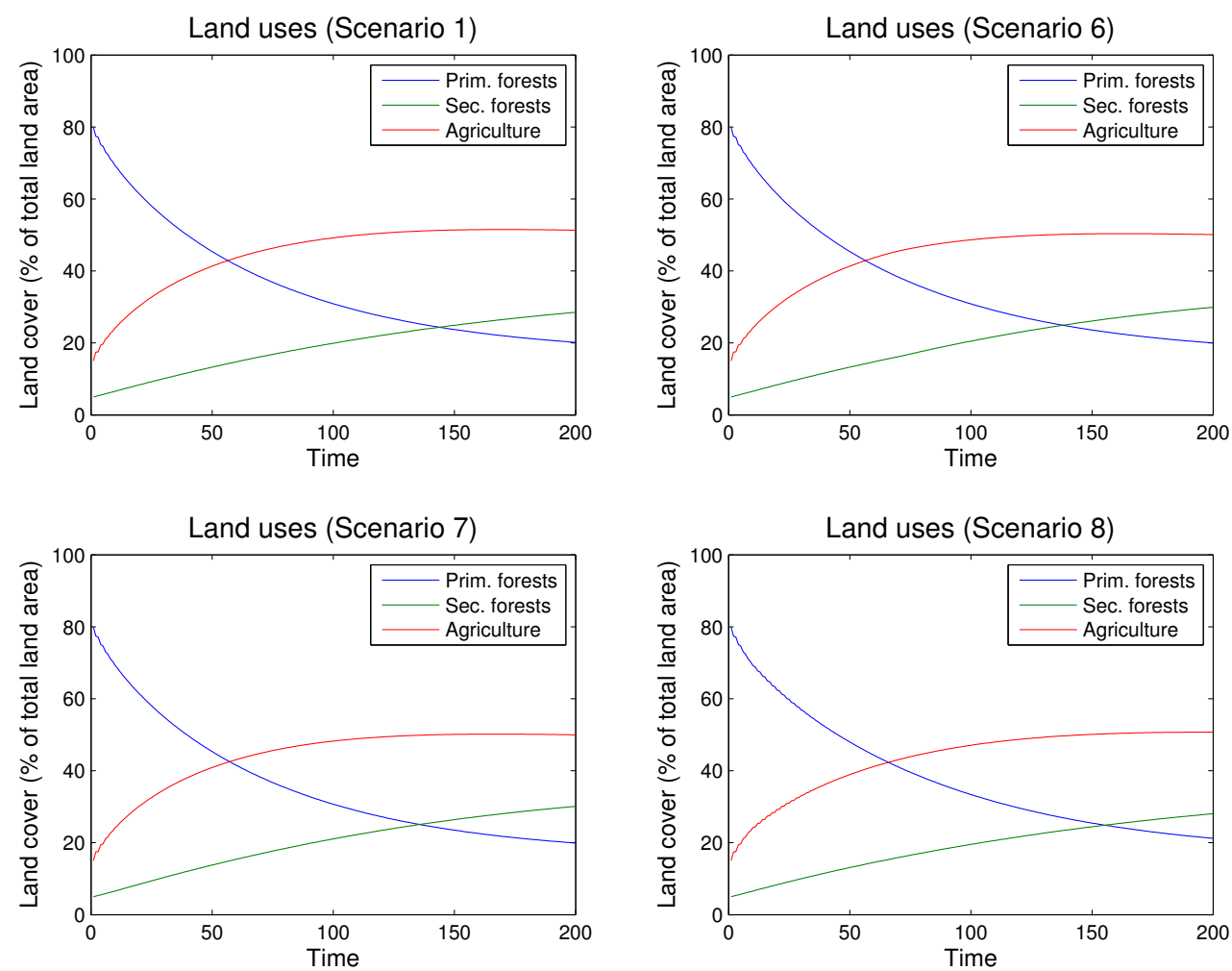

REDD+ applied to the reforestation dynamics (scenarios 6 and 7) reduces the duration of net deforestation in a given economy, as the turning point occurs earlier in time. REDD+ applied to the deforestation dynamics (scenario 8) has the opposite effect in terms of net deforestation duration, but allows to preserve more primary native forests at the end of the forest transition. Following our model, the implementation of REDD+ always allows to obtain a forest transition with a higher amount of total forest cover than in the Business-As-Usual scenario. 


\section{Appendix B: Illustration of the composition effect}

We provide details on the forest composition of 8 developing countries at different stages of forest transition. As assumed in our model, the share of secondary forests includes both regenerated and planted forests. Primary forests refer to intact forest landscapes.

Figure 8: Forest composition in 8 developing countries

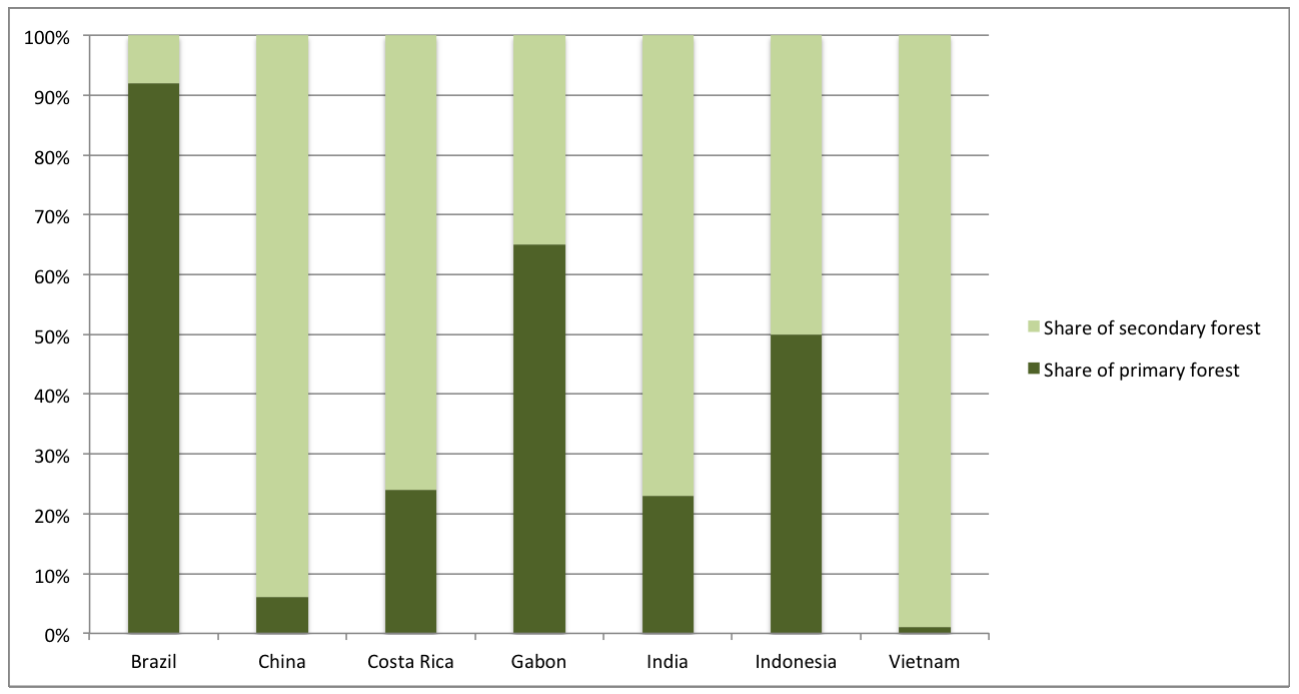

Data source: Global Forest Watch, 2014

The type of forests in countries considered as experiencing a turning point - China, Costa Rica, India, Vietnam - is mainly secondary, since the natural old-growth forests have been cleared. In countries considered as distant from the turning point, like Gabon, the forest type is primary. In Brazil, despite years of logging, the forest cover remains primary. 


\section{References}

Angelsen, A. and Rudel, T. K. (2013). Designing and implementing effective REDD+ policies: A forest transition approach. Review of Environmental Economics and Policy, 7(1):91-113. 2, 5.2

Araujo, C., Bonjean, C. A., Combes, J.-L., Motel, P. C., and Reis, E. J. (2009). Property rights and deforestation in the brazilian amazon. Ecological Economics, 68(8-9):2461 - 2468. 3.1, 5.1

Arcand, J.-L., Guillaumont, P., and Jeanneney, S. G. (2008). Deforestation and the real exchange rate. Journal of Development Economics, 86(2):242 - 262.

Asner, G. P., Keller, M., Lentini, M., Merry, F., and Souza, C. (2009). Selective logging and its relation to deforestation, in amazonia and global change. American Geophysical Union.

Barbier, E. B., Damania, R., and Léonard, D. (2005). Corruption, trade and resource conversion. Journal of Environmental Economics and Management, 50(2):229-446. 1

Bennett, M. T. (2008). China's sloping land conversion program: Institutional innovation or business as usual? Ecological Economics, 65(4):699 - 711. Payments for Environmental Services in Developing and Developed Countries. 6

Bohn, H. and Deacon, R. T. (2000). Ownership risk, investment, and the use of natural resources. American Economic Review, 90(3):526-549. 3.1, 3.1, 5.1

Burley, J. (2002). Forest biological diversity. UNASYLVA-FAO. 2

Grainger, A. (1995). The forest transition: An alternative approach. Area, 27(3):242-251. 2

Hartwick, J. M., Van Long, N., and Tian, H. (2001). Deforestation and development in a small open economy. Journal of Environmental Economics and Management, 41(3):235-251. 1, 3.2

Karsenty, A. and Ongolo, S. (2012). Can "fragile states" decide to reduce their deforestation? the inappropriate use of the theory of incentives with respect to the $\{$ REDD $\}$ mechanism. Forest Policy and Economics, 18(0):38 - 45. Emerging Economic Mechanisms for Global Forest Governance. 1, 5.1

Lambin, E. F. and Meyfroidt, P. (2010). Land use transitions: Socio-ecological feedback versus socio-economic change. Land Use Policy, 27(2):108 - 118. 2 
Luyssaert, S., Sebastiaan, L., Schulze, E., Börner, A., Knohl, A., Hessenmoller, D., Law, B., Ciais, P., and Grace, J. (2008). Old-growth forests as global carbon sinks. Nature, 455:213-215. 2

Mather, A. S. (1992). The forest transition. Area, 24(4):367-379. 1

Mather, A. S. (2007). Recent asian forest transitions in relation to forest-transition theory. International Forestry Review, 9(1):491-502. 2, 2

Ollivier, H. (2012). Growth, deforestation and the efficiency of the REDD mechanism. Journal of Environmental Economics and Management, 64(3):312 - 327. 1

Perz, S. G. and Skole, D. L. (2003). Secondary forest expansion in the brazilian amazon and the refinement of forest transition theory. Society and Natural Resources, 16(4):277-294. 2

Rudel, T. K., Coomes, O. T., Moran, E., Achard, F., Angelsen, A., Xu, J., and Lambin, E. (2005). Forest transitions: towards a global understanding of land use change. Global Environmental Change, 15(1):23 - 31. 2

Simonet, G. and Wolfersberger, J. (2014). Forest transition and redd+ in developing countries: challenges for climate change mitigation. Les Cahiers de la Chaire Economie du Climat, Information and debates Series(29).

Stephenson, N. L., Das, A. J., Condit, R., Russo, S. E., Baker, P. J., Beckman, N. G., Coomes, D. A., Lines, E. R., Morris, W. K., Ruger, N., Alvarez, E., Blundo, C., Bunyavejchewin, S., Chuyong, G., Davies, S. J., Duque, A., Ewango, C. N., Flores, O., Franklin, J. F., Grau, H. R., Hao, Z., Harmon, M. E., Hubbell, S. P., Kenfack, D., Lin, Y., Makana, J. R., Malizia, A., Malizia, L. R., Pabst, R. J., Pongpattananurak, N., Su, S. H., Sun, F., Tan, S., Thomas, D., van Mantgem, P. J., Wang, X., Wiser, S., and Zavala, M. A. (2014). Rate of tree carbon accumulation increases continuously with tree size. Nature, advance online publication(1476-4687). 2

Wolfersberger, J., Delacote, P., and Garcia, S. (2013). An empirical analysis of the cumulative nature of deforestation. Working Paper Chaire Economie du Climat. 5.1 
This page is intentionally blank - Cette page est laissée vide intentionnellement 


\section{Working Paper Series}

$n^{\circ} 2014-14$

$n^{\circ}$ 2014-14

$n^{\circ} 2014-13$
The dynamics of deforestation and reforestation in a developing economy

By Julien Wolfersberger, Gregory S. Amacher, Philippe Delacote, Arnaud Dragicevic.

Tax Policy in a Simple General Oligopoly Equilibrium Model with Pollution Permits

By Bertrand Crettez, Pierre-André Jouvet and Ludovic A. Julien

The Social Aversion to Intergenerational Inequality and the Recycling of a Carbon Tax

By Frédéric Gonand

\section{$n^{\circ} 2014-11$}

Innovation on the seed market: the role of IPRs and commercialisation rules

By Marc Baudry and Adrien Hervouet

\section{$n^{\circ}$ 2014-10}

\section{$n^{\circ} 2014-09$}

\section{$n^{\circ}$ 2014-08}

Fostering Renewables and Recycling a Carbon Tax: Joint Aggregate and Intergenerational Redistributive Effects

By Frédéric Gonand

\section{$n^{\circ}$ 2014-07}

Energy transition toward renewables and metal depletion: an approach through the EROI concept

By Florian Fizaine and Victor Court

Contact us :

Chaire Economie du Climat - Palais Brongniart (4e étage)

28 Place de la Bourse, 75002 Paris

Tel : +33 (0)173019331

Email : contact@chaireeconomieduclimat.org

\section{Climate Economics Chair}

